\title{
EVALUATION OF STABILITY OF ROPINIROLE HYDROCHLORIDE AND PRAMIPEXOLE DIHYDROCHLORIDE MICROSPHERES AT ACCELERATED CONDITION
}

\author{
KOYEL KAR ${ }^{a}$, R. N. PAL ${ }^{b}$, N. N. BALAc, GOURANGA NANDI ${ }^{c}$
}

aDepartment of Pharmaceutical Chemistry, BCDA College of Pharmacy and Technology, Hridaypur, West Bengal, India, bDepartment of Pharmaceutics, Calcutta Institute of Pharmaceutical Technology and Allied Health Sciences, Uluberia, West Bengal, India, cDepartment of Pharmaceutics, BCDA College of Pharmacy and Technology, Hridaypur, West Bengal, India

Email: koyel20@gmail.com

Received: 23 Mar 2018, Revised and Accepted: 24 May 2018

\section{ABSTRACT}

Objective: The objective of the present work was to conduct accelerated stability study as per international council for harmonisation (ICH) guidelines and to establish shelf life of controlled release dosage form of ropinirole hydrochloride and pramipexole dihydrochloride microspheres for a period of 6 mo.

\begin{abstract}
Methods: Most optimized batch of ropinirole hydrochloride and pramipexole dihydrochloride (F12 and M12 respectively) were selected and subjected to exhaustive stability testing by keeping the sample in stability oven for a period of 3 and 6 mo. Various parameters like surface morphology, particle size, drug content, in vitro drug release and shelf life were evaluated at 3 and 6 mo period. The surface morphology of the formulated microspheres was determined by scanning electron microscopy (SEM). The particle size of the microspheres was estimated by optical microscopy method. The drug content was assayed by the help of ultra-violet spectrophotometer (UV). The in vitro drug release was performed by using Paddle II type dissolution apparatus and the filtrate was analyzed by UV spectrophotometer. The shelf life of the optimized microspheres was calculated by using the rate constant value of the zero-order reaction.
\end{abstract}

Results: A minor change was recorded in average particle size of F12 and M12 microspheres after storage for 6 mo. For F12 and M12, initially the particle size was $130.00 \mu \mathrm{m}$ and $128.92 \mu \mathrm{m}$ respectively and after $6 \mathrm{mo}$ it was found to be $130.92 \mu \mathrm{m}$ and $128.99 \mu \mathrm{m}$ respectively. There was no change in surface morphology of F12 and M12 microspheres after 6 mo of storage. The shape of microspheres remained spherical and smooth after 6 mo. An insignificant difference of drug content was recorded after 6 mo compared to the freshly prepared formulation. For F12 and M12, 94.50\% and $93.77 \%$ of the drug was present initially and after $6 \mathrm{mo} 94.45 \%$ and $93.72 \%$ of the drug was recorded. In vitro drug release was recorded after 6 mo for F12 and M12. Initially, 97.99\% and 97.69\% of the drug was released till 14th hour respectively for F12 and M12. After 6 mo, 98.23\% and $97.99 \%$ of the drug was released respectively. The percentage residual drug content revealed that the degradation of microspheres was low. Considering the initial percentage residual drug content as 100\%, 99.94\% of the drug was recorded for both F12 and M12. The shelf life for F12 and M12 was found to be 10 y $52 \mathrm{~d}$ and 10 y $70 \mathrm{~d}$ respectively which were determined by the zero-order kinetic equation.

Conclusion: A more or less similar surface morphology, particle size, drug content and percent of drug release before and after stability study confirmed the stability of F12 and M12 microspheres after storage for 6 mo and prove the efficacy of the microspheres in the site-specific delivery of drugs in Parkinson's disease.

Keywords: Accelerated stability study, Shelf life, Ropinirole hydrochloride and pramipexole dihydrochloride microspheres

(C) 2018 The Authors. Published by Innovare Academic Sciences Pvt Ltd. This is an open access article under the CC BY license (http://creativecommons.org/licenses/by/4.0/) DOI: http://dx.doi.org/10.22159/ijap.2018v10i4.26184

\section{INTRODUCTION}

Drug development process plays an important role in achieving scientific success and commercial launching of the drug product. The study of storage stability is of important concern in the development of a pharmaceutical product. During the developmental stage, pharmaceutical analysis and stability studies are the most important steps required to determine and assure the identity, potency, and purity of ingredients, as well as formulated products $[1,2]$.

Stability of a pharmaceutical product is defined as the capacity of a particular formulation in a specific condition or in a specific container to maintain its physical, chemical, microbiological, therapeutical and toxicological specifications. Various chemical, physical and microbiological reactions may change the original properties of a preparation during transport, storage, and use [1, 2]. A stable drug delivery system should not only maintain its integrity and morphology but also the nature of the entrapped drug, percentage drug content and in vitro drug release rate $[1,2]$.

Drug formulation's stability testing is a complex process involving a variety of factors during which it may undergo a change in appearance, consistency, content uniformity, particle size and shape, moisture contents, $\mathrm{pH}$ and package integrity thereby affecting its stability. Various chemical reactions may occur in the pharmaceutical product such as reduction, oxidation, and racemization and may lead to the formation of the degradation product, loss of excipients and active pharmaceutical ingredient (API) potency, loss of activity etc $[1,2]$.

Stability studies ensuring the maintenance of product quality, safety and efficacy throughout the shelf life are considered a pre-requisite for the acceptance and approval of any pharmaceutical product. These studies are required to be conducted in a planned way following the guidelines issued by ICH (table 2) [1-3].

Ropinirole hydrochloride and pramipexole dihydrochloride are nonergoline dopamine $D_{2}$ receptor agonist used in the treatment of Parkinson's disease. Both the drugs undergo an extensive biotransformation, mainly through cytochrome P-450 CYP3A. They suffer from poor bioavailability $(\sim 30 \%$ to $40 \%)$ owing to an important first pass metabolism. Controlled release microspheres have been known for increasing the therapeutic efficacy and enhancing the physical as well as chemical stability of many drugs $[4,5]$. In vitro evaluation of the formulation has been extensively studied.

The rationale of the present investigation was to assess the stability profile of optimized formulation of ropinirole hydrochloride and pramipexole dihydrochloride (F12 and M12) using various combinations of eudragit RS100, eudragit RL100 and ethylcellulose at accelerated condition. In vitro characterization results showed prolonged and controlled drug release from spherical and highly entrapped microspheres. Now, during stability studies, extensive 
work on particle size, SEM, percentage drug content, in vitro drug release and percentage residual content of the formulations at accelerated conditions was conducted.

\section{MATERIALS AND METHODS}

\section{Materials}

Ropinirole hydrochloride was a gift sample provided by Central Drug Laboratory, Kolkata and pramipexole dihydrochloride was purchased from Sigma Aldrich. Eudragit RS 100 and eudragit RL 100 were purchased from Yarrow chem product, Mumbai. Ethylcellulose and magnesium stearate was purchased from Loba Chemie, Mumbai. Span 80 was purchased from Merck specialties Private Limited. The stability study was carried out in stability chamber (Thermo Lab,
Mumbai). The pure dug was of standard quality complying with official monographs. All the chemicals used for the analysis were of analytical grade complying with the official monograph.

Formulation of ropinirole hydrochloride and pramipexole dihydrochloride microspheres

Ropinirole hydrochloride and pramipexole dihydrochloride microspheres were prepared by solvent evaporation technique using a different amount of eudragit RS100, eudragit RL100 and ethylcellulose [6-8]. The formulation containing different drug: polymer ratios were coded as F1, F2, F3, F4, F5, F6, F7, F8, F9, F10, F11 and F12 for ropinirole hydrochloride and M1, M2, M3, M4, M5, M6, M7, M8, M9, M10, M11 and M12 for pramipexole dihydrochloride. The composition of various formulations is mentioned in table 1 .

Table 1: Composition of ropinirole hydrochloride and pramipexole dihydrochloride microspheres

\begin{tabular}{|c|c|c|c|c|c|c|}
\hline \multirow{2}{*}{$\begin{array}{l}\text { Formulation } \\
\text { code }\end{array}$} & \multicolumn{2}{|l|}{ Drugs used } & \multirow{2}{*}{$\begin{array}{l}\text { Drug: } \\
\text { eudragit RS } \\
100\end{array}$} & \multirow{2}{*}{$\begin{array}{l}\text { Drug: eudragit } \\
\text { RS } 100 \text { and RL } \\
100\end{array}$} & \multirow{2}{*}{$\begin{array}{l}\text { Drug: eudragit RS } 100 \\
\text { and ethylcellulose }\end{array}$} & \multirow{2}{*}{$\begin{array}{l}\text { Magnesium } \\
\text { stearate } \\
\text { (mg) }\end{array}$} \\
\hline & $\begin{array}{l}\text { Ropinirole } \\
\text { hydrochloride } \\
\text { (mg) }\end{array}$ & $\begin{array}{l}\text { Pramipexole } \\
\text { dihydrochloride } \\
\text { (mg) }\end{array}$ & & & & \\
\hline F1 and M1 & 2 & 2 & $1: 3$ & - & - & 50 \\
\hline F2 and M2 & 2 & 2 & $1: 4$ & - & - & 50 \\
\hline F3 and M3 & 2 & 2 & $1: 5$ & - & - & 50 \\
\hline F4 and M4 & 2 & 2 & $1: 6$ & - & - & 50 \\
\hline F5 and M5 & 2 & 2 & - & $1: 2.5: 0.5$ & - & 50 \\
\hline F6 and M6 & 2 & 2 & - & $1: 3: 1$ & - & 50 \\
\hline F7 and M7 & 2 & 2 & - & $1: 3.5: 1.5$ & - & 50 \\
\hline F8 and M8 & 2 & 2 & - & $1: 4: 2$ & - & 50 \\
\hline F9 and M9 & 2 & 2 & - & - & $1: 2.5: 0.5$ & 50 \\
\hline F10 and M10 & 2 & 2 & - & - & $1: 3: 1$ & 50 \\
\hline F11 and M11 & 2 & 2 & - & - & $1: 3.5: 1.5$ & 50 \\
\hline F12 and M12 & 2 & 2 & - & - & $1: 4: 2$ & 50 \\
\hline
\end{tabular}

$\mathrm{F}$ and $\mathrm{M}=$ formulation code

Methods

Accelerated stability study of ropinirole hydrochloride and pramipexole dihydrochloride microspheres

The most optimized batch of ropinirole hydrochloride and pramipexole dihydrochloride (F12 and M12 respectively) were selected and subjected to exhaustive stability testing at $40^{\circ} \mathrm{C} \pm 2{ }^{\circ} \mathrm{C}$,
$75 \% \mathrm{RH} \pm 5 \% \mathrm{RH}$ for 6 mo using stability oven (Thermo Lab, Mumbai). Samples were withdrawn at 3 and 6 mo period according to ICH guidelines (table 3) [9, 10]. Various in vitro parameters and shelf life were evaluated [11, 12].

Statistical evaluation was done using analysis of variance (ANOVA) at $\mathrm{P} \leq 0.05$ significance level and it was found to be statistically significant with $\mathrm{P}$ value $<0.05$.

Table 2: ICH guidelines for stability testing of new formulation

\begin{tabular}{lll}
\hline Study & Storage conditions & Minimum time period covered by data at submission \\
\hline Long-term & $25{ }^{\circ} \mathrm{C} \pm 2{ }^{\circ} \mathrm{C} / 60 \% \mathrm{RH}$ (relative humidity) $\pm 5 \% \mathrm{RH}$ or $30{ }^{\circ} \mathrm{C} \pm 2{ }^{\circ} \mathrm{C} / 65 \%$ & $12 \mathrm{mo}$ \\
& $\mathrm{RH} \pm 5 \% \mathrm{RH}$ & $6 \mathrm{mo}$ \\
Intermediate & $30{ }^{\circ} \mathrm{C} \pm 2{ }^{\circ} \mathrm{C} / 65 \% \mathrm{RH} \pm 5 \% \mathrm{RH}$ & $6 \mathrm{mo}$ \\
Accelerated & $40{ }^{\circ} \mathrm{C} \pm 2{ }^{\circ} \mathrm{C} / 75 \% \mathrm{RH} \pm 5 \% \mathrm{RH}$ & \\
\hline
\end{tabular}

\section{Microsphere particle size and structural integrity}

Selected formulations were stored in amber colored glass bottles at $40{ }^{\circ} \mathrm{C} \pm 2{ }^{\circ} \mathrm{C}, 75 \% \mathrm{RH} \pm 5 \% \mathrm{RH}$ for a period of $6 \mathrm{mo}$ and examined for any change in particle size and surface morphology. The particle size of the microspheres was determined by optical microscopy (Motic digital microscope, B1 Advanced series) [13]. The eyepiece micrometer was calibrated with the help of a stage micrometer. The particle diameter of more than 50 microspheres was measured randomly. The average particle size (table 3) was determined by using Edmondson's equation [Mean Particle size $=\Sigma$ (mean particle size of the fraction $x$ weight fraction) $/ \Sigma$ (weight fraction)]. The surface morphology of the microspheres was determined by SEM analysis (JEOL MAKE UK; MODEL-JSM 6360). The samples for the SEM analysis were prepared by sprinkling the microspheres on one side of an adhesive stub. The microspheres were then coated with gold [13]. Finally, the microspheres were observed with scanning electron microscope (fig. 1).

\section{Drug content}

After 3 and $6 \mathrm{mo}$, the drug content of microspheres was determined by milling and immersing the microsphere in distilled water after which they were stirred for $4 \mathrm{~h}$ (hour) and left at room temperature overnight. Then it was filtered by using Whatmann filter paper after which the volume was made up by washing the residue and assayed in UV spectrophotometer (Shimadzu-1700, Japan) $[14,15]$.

The absorbance was determined at $\lambda_{\max }$ against blank. The quantity of ropinirole hydrochloride and pramipexole dihydrochloride microencapsulated was calculated from the standard calibration curve of the drug (table 4). 
In vitro drug release studies after storage at accelerated term temperature

In vitro release studies were performed by using USP II dissolution (Paddle type). An accurately weighed sample $(75 \mathrm{mg})$ of microspheres was suspended into $900 \mathrm{ml}$ of phosphate buffer ( $\mathrm{pH}$ 7.4) maintained at a temperature of $37^{\circ} \mathrm{C} \pm 0.5^{\circ} \mathrm{C}$ and stirred at a speed of $100 \mathrm{rpm}$ (round per minute). At predetermined time intervals, a $5 \mathrm{ml}$ aliquot of the sample was withdrawn and the volume was replaced with an equivalent amount of plain dissolution medium kept at $37{ }^{\circ} \mathrm{C}$. The collected samples were filtered and analyzed at $\lambda$ max using a UV spectrophotometer (Shimadzu-1700, Japan) against buffers taken as blank [16, 17]. Percentage drug released at different time intervals were calculated using LambertBeer's equation and shown in fig. 2 and fig. 3.

\section{Percentage residual drug content and estimation of shelf life}

Microspheres of each drug $(200 \mathrm{mg})$ were milled and immersed in distilled water after which they were stirred for $4 \mathrm{~h}$ and left at room temperature overnight and then filtered with Whatmann filter paper and an aliquot of the filtrate was diluted with distilled water. The filtrate was analyzed for drug content and absorbance was measured using UV spectrophotometer (Shimadzu-1700, Japan) at different nano-meter specific to drugs $[18,19]$. The percentage residual content was calculated and reported in table 5. The degradation rate constant and shelf life (table 6) of those samples were calculated using the following formula since the drug was released following zero-order kinetics $[18,19]$.

$$
\text { Shelflife }=\frac{0.1 C_{0}}{K} \text {, where } K=\frac{C_{0}-C_{t}}{t}
$$

Where $K=$ Degradation rate constant, ${ }^{t}=$ Time in days, $C_{0}=$ Initial amount of drug and
$C_{t}=$ Concentration of drug after time $\mathrm{t}$ (or final amount)

\section{RESULTS AND DISCUSSION}

\section{Microsphere structural integrity and particle size}

A minor change was recorded in particle size of microspheres after storage for 3 and $6 \mathrm{mo}$. A linear relationship exists between the rate of degradation and particle size. In this study, the minor changes were noticed due to the humidity accelerating the aggregation of the microspheres and the evaporation of residual amount of organic solvent but the change was minimal since a constant temperature was maintained throughout the study. According to a previous study, temperature played an important role in maintaining the size of the particles. It was reported that the microspheres remained intact even after three years but as the temperature was increased, the rate of degradation also increased and hence the particle size was affected [20]. The shape of microspheres was examined by SEM which was initially spherical and smooth but there was no change in surface morphology after 6 mo of storage in case of formulations F12 and M12. The structural integrity was maintained even after six months because the polymer maintained its crystallinity. This was possible because the polymers used in this study do not have a very high molecular weight. In a previous study, it was seen that polymer molecular weight not only translates to longer degradation times but also to a change in polymer properties $[21,22]$

\section{Drug content}

On analysis of drug content of microspheres, insignificant differences were recorded after 3 and 6 mo in comparison to the freshly prepared formulations. This non-significant loss was due to a slight loss of integrity of the system. According to a previous paper, it was reported that the microspheres prepared by solvent evaporation technique did not show any change in drug content even after three-year storage under desiccated condition [23].

Table 3: Particle size after storage at different time intervals

\begin{tabular}{|c|c|c|c|c|}
\hline \multirow[t]{2}{*}{ Formulation code } & \multirow[t]{2}{*}{ Parameters } & \multicolumn{3}{|c|}{ Observation on storage for } \\
\hline & & Initial & $3 \mathrm{mo}$ & $6 \mathrm{mo}$ \\
\hline $\begin{array}{l}\text { F12 } \\
\text { M12 }\end{array}$ & Particle size & $\begin{array}{l}130.00 \pm 4.16 \\
128.92 \pm 3.00\end{array}$ & $\begin{array}{l}130.87 \pm 0.59 \\
128.95 \pm 1.25\end{array}$ & $\begin{array}{l}130.92 \pm 0.29 \\
128.99 \pm 0.99\end{array}$ \\
\hline
\end{tabular}

(mean \pm SD; $\mathrm{n}=3$ ), $\mathrm{n}=$ no. of observation, $\mathrm{F}$ and $\mathrm{M}=$ formulation code

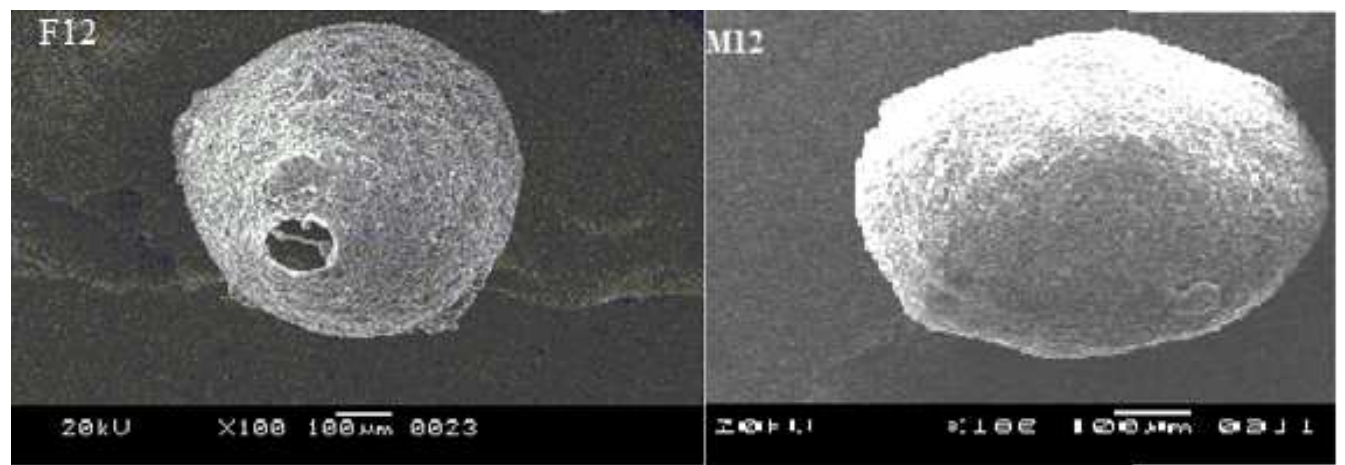

Fig. 1: Surface morphology of F12 and M12 after 6 mo

Table 4: Percentage drug content after storage at different time intervals

\begin{tabular}{|c|c|c|c|c|}
\hline \multirow[t]{2}{*}{ Formulation code } & \multirow[t]{2}{*}{ Parameters } & \multicolumn{3}{|c|}{ Observation on storage for } \\
\hline & & Initial & $3 \mathrm{mo}$ & $6 \mathrm{mo}$ \\
\hline F12 & Drug content & $94.50 \pm 0.56$ & $94.48 \pm 0.48$ & $94.45 \pm 0.43$ \\
\hline M12 & & $93.77 \pm 1.13$ & $93.75 \pm 1.48$ & $93.72 \pm 1.23$ \\
\hline
\end{tabular}

(mean $\pm S D ; n=3$ ), $\mathrm{n}=$ no. of observation, $\mathrm{F}$ and $\mathrm{M}=$ formulation code 
In vitro drug release studies after storage at accelerated term temperature

In vitro release study of the freshly prepared optimized formulations (F12 and M12) at pH 7.4 revealed that $97.99 \%$ and $97.69 \%$ of the drug was released till 14th hour respectively. After 3 mo, 98.01\% and $97.82 \%$ of the drug was released till 14 th hour respectively and after 6 mo $98.23 \%$ and $97.99 \%$ of the drug was released respectively. Thus, the difference in drug release after storage for 3 and 6 mo was insignificant. The drug release was slightly increased due to the formation of more pores in the microspheres, allowing the release of more drugs through the pores. This occurred because of the evaporation of residual amount of solvent. The rate of evaporation is directly dependent on the temperature. As a result, if the temperature increases then the drug release may increase due to faster evaporation rate. According to a previous report, under prolonged storage, temperature becomes a dominant factor causing an increase in drug release [24].

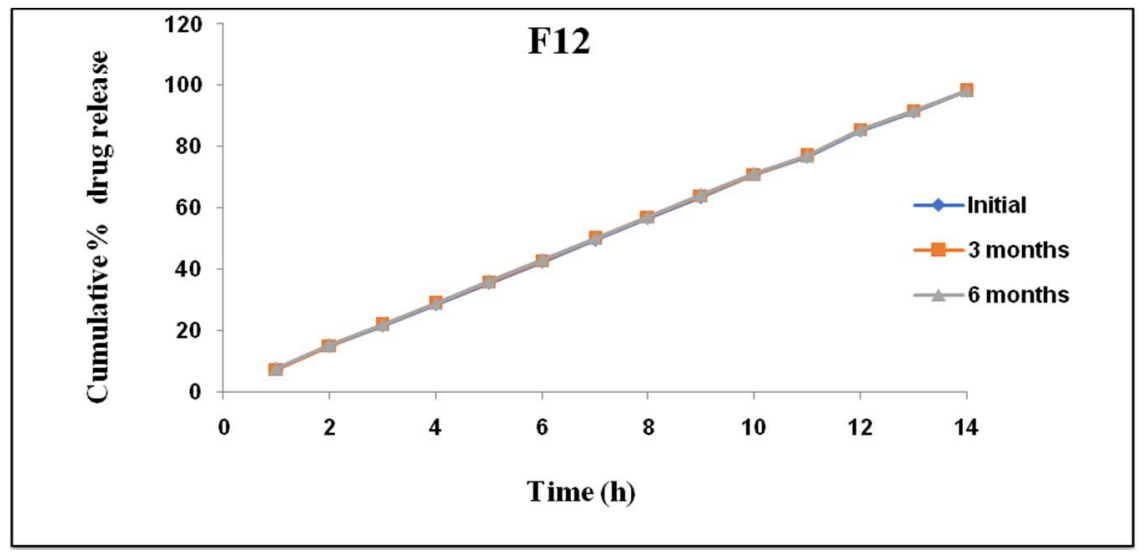

Fig. 2: Percentage cumulative drug release after 6 mo storage of F12 for $14 \mathrm{~h}$. All values are represented as mean \pm SD $(\mathrm{n}=3$ )

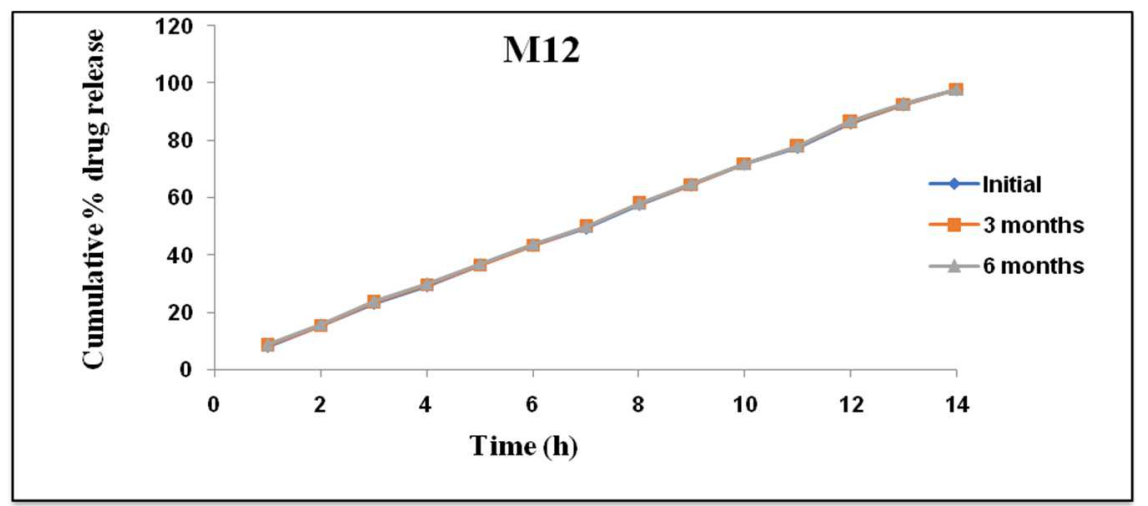

Fig. 3: Percentage cumulative drug release after 6 mo storage of M12 for $14 \mathrm{~h}$. All values are represented as mean \pm SD $(\mathrm{n}=3$ )

\section{Percentage residual drug content and shelf life}

The chemical stability study of the microspheres was carried out at accelerated temperatures. The percentage residual drug content was evaluated as a part of storage stability studies considering initial drug content as $100 \%$. The thermal degradation of F12 and M12 were studied by keeping the formulations at accelerated temperatures of $40{ }^{\circ} \mathrm{C} \pm 2{ }^{\circ} \mathrm{C} / 75 \% \mathrm{RH} \pm 5 \% \mathrm{RH}$. The degradation of microspheres was relatively very low at room temperature. Since the study was carried out at accelerated room temperature; the degradation in percentage residual content was low. According to a previous study, it was reported that temperature is directly proportional to the rate of degradation. So as the temperature was increased, the rate of degradation was also increased leading to the loss of active ingredients [25]. The shelf life of F12 and M12 was found to be 10 y $52 \mathrm{~d}$ and 10 y $70 \mathrm{~d}$ respectively. In this study, the shelf life was estimated to define the time up to which the product will remain stable under accelerated storage conditions. If the formulated product is not stored in accordance, then it would lead to degradation. In a previous study, it was reported that for new drugs it is a general practice to grant only two-year expiry initially for a six-month accelerated study and the shelf life for later years would be allowed only on production of real-time data for the subsequent years [26].

Table 5: Percentage residual drug content from optimized formulations on storage at an accelerated temperature

\begin{tabular}{|c|c|c|c|}
\hline \multirow[t]{2}{*}{ Formulation code } & \multicolumn{3}{|c|}{ \% Residual drug content on storage at accelerated temperature } \\
\hline & Initial & $3 \mathrm{mo}$ & $6 \mathrm{mo}$ \\
\hline F12 & 100 & $99.98 \pm 0.85$ & $99.94 \pm 1.70$ \\
\hline M12 & 100 & $99.97 \pm 0.39$ & $99.94 \pm 0.42$ \\
\hline
\end{tabular}

(mean $\pm S D ; n=3$ ), $\mathrm{n}=$ no. of observation, $\mathrm{F}$ and $\mathrm{M}=$ formulation code 
Table 6: Shelf life of the optimized formulations after storage at an accelerated temperature

\begin{tabular}{llll}
\hline S. No. & Formulation code & Value of $\mathbf{k}$ & Value of t $\mathbf{9 0 \%}$ (d) \\
\hline 1 & F12 & 0.00273 & 3841.46 \\
2 & M12 & 0.00240 & 3907.08 \\
\hline
\end{tabular}

$\mathrm{F}$ and $\mathrm{M}=$ formulation code, $\mathrm{k}=$ zero-order rate constant, $\mathrm{t}_{90 \%}=$ shelf life

\section{CONCLUSION}

Once the delivery system is developed, the practical utility of the formulation depends on the maintenance of the therapeutic efficacy throughout the shelf life under different storage conditions. Prediction of stability of a dosage form is necessary due to legal, moral, economic, competitive and public health reason. Various in vitro characterization parameters of the microsphere was assessed after storage of the formulation for 3 and $6 \mathrm{mo}$ at $40{ }^{\circ} \mathrm{C} \pm 2{ }^{\circ} \mathrm{C} / 75 \% \mathrm{RH} \pm 5 \% \mathrm{RH}$ according to ICH guidelines and results were compared with those obtained before storage. A minor change was recorded in average particle size of F12 and M12 microspheres after storage for 3 and 6 mo. The shape of F12 and M12 microspheres were examined by SEM and there was no change in surface morphology after 3 and 6 mo of storage. On analysis of drug content of F12 and M12 microspheres, insignificant differences were recorded after 3 and 6 mo in comparison to the freshly prepared formulation. The difference in drug release after storage for 3 and 6 mo was insignificant. A more or less similar percent of drug release before and after stability study confirmed the stability of F12 and M12 microspheres after storage for 6 mo and proves the efficacy of the microspheres in the site-specific delivery of drugs in Parkinson's disease. The percentage residual drug content revealed that the degradation of microspheres was relatively very low and the shelf life for F12 and M12 was found to be 10 y $52 \mathrm{~d}$ and 10 y $70 \mathrm{~d}$ respectively.

\section{ACKNOWLEDGMENT}

The authors are highly thankful to BCDA College of Pharmacy and Technology, Barasat and Bharat Technology, Uluberia, India for providing all the facilities to carry out the research work.

\section{AUTHORS CONTRIBUTIONS}

Koyel Kar carried out the research work and wrote the manuscript. Dr. R. N. Pal, Dr. N. N. Bala and Dr. G. Nandi contributed to the article with a critical revision. All authors read and approve the final manuscript.

\section{CONFLICT OF INTERESTS}

The authors have none to declare

\section{REFERENCES}

1. Cha J, Gilmor T, Lane P, Ranweiler JS. Stability studies in Handbook of modern pharmaceutical analysis. Drug Dev Indus Pharm 2001;10:459-505.

2. Carstensen JT, Rhodes CT. Rationale policies for stability testing. Clin Res Regulatory Affairs 1993;10:177-85.

3. Puthli SP, Vavia PR. Stability studies of micro-particulate system with piroxicam as model drug. AAPS Pharm Sci Tech 2009;10:872-80.

4. Saffari M, Shahbazi M, Ardestani MS. Formulation and in vitro evaluation of Eudragit L100 microspheres of piroxicam. Nature Prec 2008;1:1544-7.

5. Azeem A, Iqbal Z, Ahmad FJ, Khar RK, Talegaonkar S. Development and validation of a stability-indicating method for determination of ropinirole in the bulk drug and in pharmaceutical dosage forms. Acta Chromatogr 2008;20:95-107.

6. Kim BK, Hwang SJ, Park JB, Park HJ. Preparation and characterization of drug-loaded polymethacrylate microspheres by an emulsion solvent evaporation method. J Microencapsul 2002;19:811-22.
7. Deshmukh M, Mohite S. Formulation and characterisation of olanzepine loaded mucoadhesive microspheres. Asian J Pharm Clin Res 2017;10:249-55.

8. Durgapal S, Mukherjee S, Goswami L. Preparation, characterization and evaluation of floating microparticles of ciprofloxacin. Int J Appl Pharm 2017;9:1-8.

9. Guideline IH. Stability testing guidelines: stability testing of new drug substances and products. ICH Q1A (R2) (CPMP/ICH/2736/99); 1999.

10. Singh S. Stability testing during product development. In: Jain NK. Pharmaceutical product development. CBS publisher and distributors India; 2000. p. 272-93.

11. Kommanaboyina B, Rhodes CT. Trends in stability testing, with emphasis on stability during distribution and storage. Drug Dev Ind Pharm 1999;25:857-67.

12. Tyagi LK, Kori ML. Stability study and in vivo evaluation of lornoxicam loaded ethyl cellulose microspheres. Int J Pharm Sci Drug Res 2014;6:26-30.

13. Sharma M, Kohli S, Pal A. Stability of floating microspheres at normal and accelerated conditions. Int J Pharm Pharm Sci 2016;8:452-4.

14. Puthli SP, Vavia PR. Stability indicating HPTLC determination of piroxicam. J Pharm Biomed Anal 2000;22:673-7.

15. Bajaj S, Singhla D, Sakhuja N. Stability testing of pharmaceutical products. J Appl Pharm Sci 2012;2 Suppl 3:129-38.

16. Johansen P, Men Y, Audran R, Corradin G, Merkle HP, Gander B. Improving stability and release kinetics of microencapsulated tetanus toxoid by co-encapsulation of additives. Pharm Res 1998;15:1103-10.

17. Singh S, Bakshi M. Guidance on the conduct of stress test to determine the inherent stability of drugs. Pharm Technol Asia 2000;24:1-14.

18. Kohli S, Pal A, Jain S. Preparation, characterization and evaluation of Poly (Lactide-co-Glycoside) microsphere for the controlled release of zidovudine. Int J Pharm Pharm Sci 2017;9:70-7.

19. Sayin B, Calis S. Influence of accelerated storage conditions on the stability of vancomycin loaded poly (D, L-Lactide-coglycolide) microspheres. FABAD J Pharm Sci 2004;29:111-6.

20. Dunne M, Corrigan OI, Ramtoola Z. Influence of particle size and dissolution conditions on the degradation properties of polylactide-co-glycolide particles. Biomaterials 2000;21:1659-68.

21. Chacon M, Molpeceres J, Berges L, Guzman M, Aberturas MR. Stability and freeze drying of cyclosporine loaded poly (D, L lactide-glycolide) carriers. Eur J Pharm Sci 1999;8:99-107.

22. Donnell PB, McGinity JW. Influence of processing on the stability and release properties of biodegradable microspheres containing thioridazine hydrochloride. Eur J Pharm Biopharm 1998;45:83-94.

23. Delgado A, Evora C, Llabres M. Effect of storage on the stability of DL-PLA microspheres containing methadone. Int J Pharm 1998;166:223-5.

24. Lewis L, Boni RL, Adeyeye CM. The physical and chemical stability of suspensions of sustained-release diclofenac microspheres. J Microencapsulation 1998;15:555-67.

25. Carstensen JT. Drug stability, principles and practices. $2^{\text {nd }}$ ed. New York: Marcel Dekker Publishers; 2000.

26. Singh S. Drug stability testing and shelf-life determination according to international guidelines. Pharm Technol 1999;23:68-88. 